\title{
Review on Dietary Contribution of Wild Edible Food Biodiversity to Food Security and Micronutrient Status of Children in Ethiopia
}

\author{
Tamiru Yazew \\ Department of Food Science and Nutrition, College of Agriculture, Wollega University, Shambu, Ethiopia \\ Email address: \\ tamiruyazew2012@gmail.com

\section{To cite this article:} \\ Tamiru Yazew. Review on Dietary Contribution of Wild Edible Food Biodiversity to Food Security and Micronutrient Status of Children in \\ Ethiopia. Journal of Health and Environmental Research. Vol. 6, No. 1, 2020, pp. 27-30. doi: 10.11648/j.jher.20200601.13
}

Received: December 31, 2019; Accepted: March 13, 2020; Published: April 14, 2020

\begin{abstract}
Deficiencies in key vitamins and minerals are placed among the major public health problems. In Ethiopia, children aged 6-59 months are dramatically affected by vitamin A deficiency and iron deficiency anemia, which accounts $61 \%$ and $54 \%$, respectively. Nationally, the prevalence of anemia among children under two years was $56 \%$. The objective of this review was to document current information regarding dietary contribution of wild edible food biodiversity to food security and micronutrient status of children in Ethiopia. Magnitude of under nutrition, low dietary diversity and food insecurity in Ethiopia is very high in rural communities where livelihood depends on backward farming system. The nutritional consequences of food insecurity experience include under nutrition depending on a broad range of contextual, economic and socio cultural factors. Although, Ethiopia is among the regions producing adequate wild edible food biodiversity in the Africa, it is reported that there is high prevalence rate of micronutrient deficiencies compared to prevalence in less productive regions of Africa. Therefore, all responsible bodies should be intensified and incorporated to reduce food insecurity and micronutrient deficiencies through nutrition education intervention. In the future, researchers should also conduct the nutritional composition, phytochemicals and antioxidants of each wild edible food biodiversity in Ethiopia.
\end{abstract}

Keywords: Wild Edible Food Biodiversity, Food Insecurity, Micronutrient Deficiencies, Ethiopia

\section{Introduction}

Deficiencies in key vitamins and minerals are placed among the major public health problems. In Ethiopia, children are dramatically affected by vitamin A deficiency and iron deficiency anemia, affecting around $61 \%$ and $54 \%$, respectively [4]. Nationally, the prevalence of anemia among children under two years was $56 \%$ [5].

The burden of food insecurity and malnutrition remains a global challenge [15], 2010), especially in sub-Saharan Africa, where the number of hungry and undernourished people has increased between 2014 and 2016 [11]. Despite the overall progress to reduce global food insecurity and chronic undernourishment, Sub Saharan Africa remains the most food-insecure region in the world with close to 223 million people undernourished [11]. The limited decline in under nutrition rates being linked to low levels of household food security.
In Ethiopia, magnitude of under nutrition, low dietary diversity and food insecurity is very high in rural areas where livelihood depends on backward farming system [26]. The nutritional consequences of food insecurity experience include under nutrition depending on a broad range of contextual, economic and socio cultural factors [14]. According to a study done in Tigray region, Ethiopia, the prevalence of stunting, underweight and wasting in food insecure households was high and $52.1 \%, 20.5 \%$ and $12.6 \%$, respectively [18].

Although Ethiopia is among the regions producing adequate wild edible food biodiversity in the Africa, it is reported that there is high prevalence rate of micronutrient deficiencies compared to prevalence in less productive regions of Africa [16].

Global food security and economic growth now depends on a declining number of plant species. In human history, 40-100,000 plant species have been regularly used for food, 
fibers, shelter, industrial, cultural and medicinal purposes [28]. However, only a small number of plants are widely used and the remaining plant diversity is underutilized.

The diversity of species used in agricultural and livelihood systems is essential for human nutrition and sustainable food systems [25]. Agricultural biodiversity contributes to farm resilience, particularly in the face of shocks such as climate change, disease outbreaks, and market price fluctuations [34]. Wild food diversity, obtained in or around agricultural fields or extracted from forests and other natural landscapes, is an additional source of resilience in the food system, in particular during the lean season [25].

A study done in southern Ethiopia [13] showed that wild edibles constituted good amounts of nutrients essential in human diet i.e. green leafy vegetables gave $1.5-5.8 \%$ ether extractives and total mineral composition of $12.5 \%-25.6 \%$; $\mathrm{Ca}$ being highest (1100 - $3419 \mathrm{mg} \%$ ) and $\mathrm{Fe}, \mathrm{Mg}, \mathrm{Mn}$ and $\mathrm{Zn}$ ranged from 11.7-23.14, 175-2049, 3.4-9.9 and 1.2-3.3 mg\%, respectively.

Underutilized plants contribute immensely to family food security and serve as means of survival during times of drought, famine, shocks and risks [3]. They can also supplement nutritional requirements due to their better nutritional value [17]. Many neglected and underutilized species are nutritionally rich and adapted to low input agriculture. The erosion of these species can have immediate consequences on the nutritional status and food security of the poor [25].

Therefore, this review was designed to document current information about the dietary contribution of wild edible food biodiversity to food security and micronutrients of children in Ethiopia.

\section{Literature Review}

\subsection{Food Insecurity}

Globally, about 842 million people were incapable of getting their dietary energy requirements. Out of these 842 million, the vast majority of hungry people (98.2\%) live in developing regions [11]. This shows that around one in eight people in the world are likely to have suffered from chronic hunger, not having enough food for an active and healthy life.

In terms of food security, Ethiopia is one of the seven African countries that constitute half of the food insecure population in Sub-Saharan Africa [30]. About 10\% of Ethiopia's citizens are chronically food insecure and 2.7 million people required emergency food assistance in 2014 and 238,761 children required treatment for severe and acute malnutrition in 2014 [9].

According to a study done in West Gojjam, Ethiopia, food insecurity was significantly associated with wasting [22, 2]; it also reported that the prevalence of being stunted or underweight were significantly higher for children in food insecure households of Bangladesh, Ethiopia and Vietnam. The Malaysian study has also revealed that the prevalence of stunting, underweight and wasting in the food insecure households was $54.7 \%, 53.8 \%$ and $27.0 \%$ respectively [22].

In Ethiopia, $44 \%$ of children were stunted, $10 \%$ wasted and $33 \%$ of the children were underweight [4]. The survey further shows that the prevalence of children stunted, underweight and wasted was reduced to $40 \%, 9 \%$ and $25 \%$, respectively [5]. However, the prevalence of malnutrition among different regions of Ethiopia is varied. For example, in Tigray, Afar and Oromia regions, the prevalence of children stunted was $44.4 \%, 49.2 \%$ and $37.5 \%$, respectively while underweight was $30.1 \%, 45.6 \%$ and $27.9 \%$, respectively in these regions of Ethiopia [5].

\subsection{Dietary Diversity}

All people need a variety of foods to meet requirements for essential nutrients. Consumption of adequate foods contributes to improved growth, health and development of young children [32]. However, lack of dietary diversity is a problem at any age, but it is particularly critical for infants and young children during the complementary feeding period [30]. Besides, nutritionists have long recognized children dietary diversity as a key element of high quality diet and increasing the variety of foods consumed by most dietary guidelines [32]. As dietary diversity is improved, it ultimately increases the energy and nutrients intake and thus, is significantly associated with weight-for-age, length-for-age and weight-for length [6].

Emphasizing dietary diversity especially in developing countries is particularly important for micronutrient status and nutrient adequacy. However, it was shown to be strongly dependent on household's socioeconomic status [2]. Families with greater incomes tend to have diets that are more diverse and their children grow better for a number of reasons [8].

According to a study done in Sri Lanka, the main food groups (staple foods) consumed by children in a household were cereals, roots and tuber products while animal source foods and dairy products were generally less consumed [19]. Consequently, chronic under nutrition is very high among children who ate monotonous, undiversified diets [16].

\subsection{Micronutrient Deficiencies}

Dietary micronutrient deficiencies are the most prevalent nutritional deficiencies causing serious developmental problems in the world and it is an important outcome indicator of poor nutrition and health [33]. It significantly associated with low birth weight, sex, age, residence, infectious disease, under nutrition, poor wealth status and household food insecurity [2]. Globally, in 2011, nearly one in four children under-five years of age (165 million or $26 \%$ were stunted, 101 million or $16 \%$ underweight and 52 million children under five were moderately or severely wasted [30].

Iron, vitamin A, zinc, and iodine are important micronutrients for growth, development, and survival of children, making them important micronutrients in global public health terms [32]. Both iron deficiency anemia as well as iodine deficiency disorders are known to adversely affect 
cognitive development in children which may result in lower educational achievements and hence impact economic development negatively. Both vitamin A and zinc deficiencies increase the risk of mortality in children as they are particularly vulnerable to micronutrient deficiencies due to relatively high requirements of micronutrients for growth and development.

\subsection{Wild Edible Food \& Their Importance}

A study done by [20] described the nutrition and antinutritional value of 23 unconventional wild edible plants. These plants were analyzed for proximate and mineral composition, starch, vitamins, in-vitro protein digestibility, in-vitro starch digestibility and certain antinutritional factors. The tubers of Kedrostis foetidissima and stem of Caralluma pauciflora contain higher contents of crude protein [23]. Another study done by [7] reported that 41 neglected and underutilized crop species among which 19 species were identified as of priority base on 10 criteria among which included their extent and degree of consumption. Another study done in Nigeria [1] studied sixty underutilized flowering plant species as vegetable from the field. In addition, [24] investigated uses of neglected and underutilized plant species in Nigeria. Moreover, In Ethiopia [27] recorded 33 underutilized wild edible plants in the Chilga district, northwestern Ethiopia. Of the recorded plants, $76 \%$ of fruits were the most frequently used plant parts.

Another study done elsewhere also showed that underutilized food legume species were analyzed for proximate composition, mineral profiles, vitamins, fattyacid profiles, amino acid profiles of seeds, protein digestibility and anti-nutritional factors. The crude protein ranged from $14.28-19.40 \%$, crude lipid $3.28-4.41 \%$, total dietary fiber $6.39-8.44 \%$, ash $2.80-3.50 \%$ and carbohydrate $60.29-72.51 \%$ [21].

According to a study done by [20], the relative importance of 49 underutilized plant species by using relative importance technique and they divided plant species in to six categories based on consumption. Another study also investigated the proximate composition, mineral profile, vitamins, protein fractions, fatty acid profiles and amino acid profiles of total seed protein, in vitro protein digestibility and ant-nutritional potential of legume Mucuna [29].

\section{Conclusion}

In Ethiopia, magnitude of under nutrition, micronutrient deficiencies and food insecurity are very high. The nutritional consequences of food insecurity experience include under nutrition depending on a broad range of contextual, economic and socio cultural factors. The diversity of species used in agricultural and livelihood systems is essential for human nutrition and sustainable food systems. Underutilized plants contribute immensely to family food security and serve as means of survival during times of drought, famine, shocks and risks. Therefore, a nutrition education intervention through behavioral chance communication (BCC) should be provided to ensure knowledge and perceptions of communities to consume wild edible foods and diversify their diet to overcome food insecurity and micronutrient problems.

\section{Acknowledgements}

The author forward his special thanks to Mr. Agama Daba who have a great contribution and moral support during the entire work this manuscript. The author also thanks Wollega University for finical support during the writing of this paper.

\section{References}

[1] Abubakar S, Ogbadu GH, Usman AB, Segun O, et al. The underutilized vegetable plants of the federal capital territory Abuja of Nigeria. International Journal of Development and Sustainability. 20121 (3): 34-643.

[2] Ali D, Saha KK, Nguyen PH, Diressie MT, et al. Household Food Insecurity Is Associated with Higher Child Undernutrition in Bangladesh, Ethiopia, and Vietnam, but the Effect Is Not Mediated by Child Dietary Diversity. Journal of Community and International Nutrition. 2013 Volume 143: pp.

[3] Assefa A, Abebe T: Wild edible trees and shrubs in the semi-arid lowlands of southern Ethiopia. J Sci Dev. 2011, 1: $5-19$.

[4] Central Statistical Agency of Ethiopia. Ethiopian Mini Demographic and Health Survey. 2014.

[5] Central Statistical Agency of Ethiopia Addis Ababa, Ethiopia. 2011.

[6] Christina A. Dietary Diversity is Associated with Nutrient Intakes and Nutritional Status of children in Ghana. Asian Journal of Medical Sciences. 2011; Vol 2: 105-109.

[7] Dansi A, Vodouh R, Azokpota P, et al. Diversity of the Neglected and Underutilized Crop Species of Importance in Benin. The Scientific World Journal, 2012, 1-19.

[8] Degnet A\& Tadiwos Z. Determinants of Child Malnutrition: Empirical Evidence from Kombolcha District of Eastern Hararghe Zone, Ethiopia. Quarterly Journal of International Agriculture. 2013 Volume 52 (4): 357-372.

[9] Endalew B, Muche M \& Tadesse S. Assessment of Food Security Situation in Ethiopia: A Review. Asian Journal of Agricultural Research, 2015; 9: 55-68.

[10] FAO. Guidelines for measuring household and individual dietary diversity. Rome, Italy, 2008.

[11] FAO. International Fund for Agricultural Development \& World Food Program. The State of Food Insecurity in the World: Rome, FAO, 2014.

[12] FAO. Second Report on the State of the World's Plant Genetic Resources for Food and Agriculture, Rome, 2010.

[13] Getachew A, Zemede A and Zerihun W. The Role of Wild and Semi-wild Edible Plants in Household Food Sovereignty in Hamer and Konso Communities, South Ethiopia; Ethnobotany Research \& Applications 2013, 11: 251-271. 
[14] Ghattas H. Food Security and Nutrition in the context of the Global Nutrition Transition. Technical Paper. FAO, Rome, 2014.

[15] Godfray, HCJ, Beddington, JR, Crute IR, et al. Food security: The challenge of feeding 9 billion people. Science; 2010; 327, 812-818.

[16] Hirvonen A and Hoddinott J. Targeting food security interventions when "everyone is poor": The case of Ethiopia's Productive Safety Net Programme International Food Policy Research Institute, 2014.

[17] Hunde D, Njoka J, Zemede A, Nyangito M: Wild edible fruits of importance for human nutrition in semiarid parts of east shewa zone, Ethiopia: associated indigenous knowledge and implications to food security. Pak J Nutr. 2011, 10: 40-50.

[18] Kahsay A, Mulugeta A \& Seid O. Nutritional Status of Children aged 6-59 months from Food Secure and Food Insecure Households in Rural Communities of Saesie Tsaeda-Emba District, Tigray, North Ethiopia: Comparative Study. Clinical Medicine Res. 2015 Vol 4 (1): pp. 51-65.

[19] Kandeepan K, Balakumara S \& Arasaratnama V. Nutritional status and food insecurity among the children in Northern Sri Lanka. Procedia Food Science; 2016 6: pp 220-224.

[20] Kunwar RM, Mahat L, Sharma LN, et al. Underutilized Plant Species in Far West Nepal. The Journal of Mountain Science. 2012; 9: 589-600.

[21] Mohan VR, Kalidass C. Nutritional and Antinutritional Evaluation of Some Unconventional Wild Edible Plants. Tropical and Subtropical Agro ecosystems; 2010 12: 495-506.

[22] Motbainor A, Worku A \& Kumie A. Stunting Is Associated with Food Diversity while Wasting with Food Insecurity among Underfive Children in East and West Gojjam Zones of Amhara Region, Ethiopia. PLoS One. 2015 Vol 10 (8).

[23] Naser IA, Jalil RA \& Abdullah MR. Assessment of Food Insecurity and Nutritional Outcomes in Bachok, Kelantan. Journal of Nutrition and food science. 2015; 5: 3.

[24] Osewa SO, Alamu O, Adetiloye IS, Olubiyi MR, Abidogun EA Use of some Neglected and Underutilized Plant Species among
Rural Dwellers in Akinyele Local Government Area of Oyo State. Greener Journal of Agricultural Sciences. 2013; 3 (12): 817-822.

[25] Powell B. Improving diets with wild and cultivated biodiversity from across the landscape. Food Secur 2015; 7: 535-554.

[26] Sarah CB, Daniel OG, John H, Neha K, Alemayehu S \& Wiseman W. Targeting Food Security Interventions: The Case of Ethiopia's Productive Safety Net Program. International Food Policy Research Institute, 2013.

[27] Tebkew M, Asfaw Z, Solomon Z. Underutilized wild edible plants in the Chilga District, northwestern Ethiopia: focus on wild woody plants. Agriculture \& Food Security; 2015; 3 (12): $1-16$.

[28] Teketay D, Senbeta F, Maclachlan M, et al. Edible Wild Plants in Ethiopia. Addis Ababa University Press, Addis Ababa, Ethiopia, 2010.

[29] Tresina PS, Mohan VR. Assessment of Nutritional and Antinutritional Potential of Underutilized Legumes of the Genus Mucuna. Tropical and Subtropical Agro ecosystems; 2013; 16: 155-169.

[30] UNICEF. Assessment of food security in Ethiopia. Asian Journal of Agriculture, 2014.

[31] UNICEF. Improving child nutrition, the achievable imperative for global progress, 2013.

[32] Veerabahu Ramasamy Mohan, Chinnamadasamy Kalidass. Nutritional and antinutritional evaluation of some unconventional wild edible plants. Tropical and Subtropical Agroecosystems, 12 (2010): 495-506.

[33] WHO (2010). Millennium Development Goals: progress towards the health-related Millennium Development Goals. Fact sheet Levels and Trends in Child.

[34] Zimmerer KS. Understanding agrobiodiversity and the rise of resilience: Analytic category, conceptual boundary object or meta-level transition? Resilience. 2015; 3: 183-198. 